DOI: $\underline{\text { https://doi.org/10.24867/02HZ05Misanovic }}$

\title{
FOTODEGARDACIJA IBUPROFENA U VODENOM RASTVORU PRIMENOM SMEŠE NANOKATALIZATORA ${\mathrm{ZnO} / \mathrm{TiO}_{2}}$ \\ PHOTOCATALYTIC DEGRADATION OF IBUPROFEN BY A MIXTURE OF ZnO/TiO NANOPARTICLE POWDER
}

\author{
Natalija Mišanović, Dragana Štrbac, Fakultet tehničkih nauka, Novi Sad
}

\begin{abstract}
Oblast - INŽENJERSTVO ŽIVOTNE SREDINE
Kratak sadržaj - U radu je ispitivana efikasnost fotokatalitičke razgradnje ibuprofena $u$ vodenoj sredini uz korišćenje fotokatalizatora na bazi mešavine nanočestičnog praha, koji je aktiviran UV zračenjem. Rezultati ukazuju na opravdanost kombinovanja cink oksida sa titanijum (II) oksidom u cilju povećanja efikasnosti fotokatalitičkog procesa razgradnje ibuprofena i otvaraju perspektivu da se nekim drugim mešavinama ovi rezultati mogu i poboljšati.
\end{abstract}

Ključne reči: fotokataliza, ibuprofen, mešavina nanoprahova

Abstract - In this paper, the efficiency of photocatalytic degradation of ibuprofen in the aqueous medium using photocatalysts based on nanoparticle powder which is activated by $U V$ radiation, has been examined. The results indicates the justification of the combination of zinc oxide with titanyum (II) oxide in order to increase the efficiency of the photocatalytic decomposition process of ibuprofen and opens the prospect that some other mixtures could also improve these results.

Key words: photocatalysis, ibuprofen, nanoparticle powder

\section{UVOD}

Značaj vode je velik i mnogostruk za ceo živi svet, pre svega zbog činjenice da voda predstavlja uslov života. Na Zemlji trenutno postoje dovoljne količine vode za sav živ svet, uključujući i čoveka, ali je glavni problem upravo taj što je čovek koristi neracionalno i na taj način je $i$ zagađuje [1].

Razvojem civilizacije ljudi su uporno ignorisali znake upozorenja o tome da njihove različite aktivnosti mogu ugroziti kapacitet ekosistema koji je danas neophodan za naš opstanak na Zemlji.

Danas je svest o tome da $\mathrm{u}$ potpunosti zavisimo od produktivnosti ekosistema, koja je određena kvalitetom njegovih osnovnih činilaca, zemljišta i vode, na mnogo višem nivou.

Ljudi su sada takođe svesni velikih finansijskih resursa koji su neophodni za vraćanje degradiranih prostora $\mathrm{u}$ stanje zadovoljavajućeg kvaliteta.

\section{NAPOMENA:}

Ovaj rad proistekao je iz master rada čiji mentor je bila dr Dragana Štrbac, vanred.prof.
Organski mikropolutanti kao što su farmaceutski proizvodi, proizvodi za ličnu higijenu i negu, biocidi i pesticidi nakon tretmana zaostaju $\mathrm{u}$ efluentu u konvencionalnim postrojenjima za prečišćavanje otpadnih voda, što dovodi do njihovog oslobađanja u površinske tokove.

Navedena jedinjenja su proizvedena sa ciljem da budu biološki aktivna i kao takvi mogu imati negativno dejstvo na osetljive vodene organizme čak i pri niskim koncentracijama. Iz ovog sledi da je prečišćavanje voda kontaminiranih kompleksnim organskim jedinjenjima, kao što su farmaceutski proizvodi, jedan od značajnih izazova u procesu restauracije životne sredine.

U procesu prečišćavanja otpadnih voda najbolje su se pokazali procesi oksidacije i metod heterogene katalize. Pri fotokatalitičkoj razgradnji perzistentnih polutanata koristi se čitav niz poluprovodničkih materijala i metalnih oksida od kojih najveću efikasnost daju $\mathrm{ZnO}$ i $\mathrm{TiO}_{2}$.

Prednosti titanijum dioksida leže u njegovoj visokoj fotokatalitičkoj efikasnosti, hemijskoj stabilnosti, netoksičnosti, širokoj rasprostranjenosti i niskoj ceni, ali se po sposobnosti razgradnje pojedinih organskih jedinjenja pokazao daleko inferiornijim od $\mathrm{ZnO}$ [2]. Upotreba medikamenata je u današnje vreme povećana do ekstremnih granica.

U svetu se godišnje proizvede nekoliko hiljada tona nesteroidnih antiinflamatornih lekova. Lekovi i njihovi metaboliti iz različitih izvora (domaćinstva, bolnice, industrijske i gradske otpadne vode), prolaze bez dalje razgradnje kroz sisteme za prečišćavanje i kontaminiraju površinske vode.

\section{TEORIJSKA RAZMATRANJA}

\subsection{Farmaceutski proizvodi u životnoj sredini}

Poslednju deceniju obeležio je velik broj istraživanja $u$ oblasti životne sredine kada se pojmu EOCs (Emerging organic contaminants) poklanja puno pažnje. Ovo je pojam koji ne uključuje samo novosintetizovane komponente već i novorazvijene komponente u okolini, koje se koriste duži vremenski period i mogu imati potencijalno negativne efekte na životnu sredinu poput farmaceutika i sredstava za ličnu higijenu, pesticide, veterinarske proizvode i drugo [3].

Farmaceutici predstavljaju grupu EOS koje su prisutne u životnoj sredini i pojavljuju se konstantno u veoma niskim koncentracijama. Farmaceutici i sredstva za ličnu higijenu nedavno su identifikovani u životnoj sredini kao hemikalije čija pojava dovodi do zabrinutosti, a kako navode stručnjaci ona je najčešće rezultat ispuštanja 
komunalnih otpadnih voda, jer se njihove komponente ne uklanjaju u potpunosti prilikom tretmana. Razvijene zemlje kao što su Amerika, Japan, Nemačka su najveći proizvođači farmaceutika.

U Evropskoj Uniji se oko 3.000 aktivnih komponenti farmaceutika primenjuje u ljudskoj medicini [4]. Farmaceutici, za koje se smatra da su novonastali zagađivači životne sredine zbog svog štetnog uticaja na endokrini sistem, mogu biti prirodni ili proizvedeni sintetički.

Uopšteno, farmaceutici su napravljeni sa namerom visoke stabilnosti efekata na ljude tako da biohemijskim procesima budu metabolizovani u potpunosti. Mogu biti uklonjeni iz ljudskog tela nakon delimične ili potpune konverzije u vodeni rastvor metabolita ili, u nekim slučajevima, bez metabolizacije.

Prisustvo farmaceutika u akvatičnim ekosistemima, prvenstveno u pijaćoj vodi trebalo bi razmatrati kao važnu tematsku oblast sa aspekta zaštite ljudskog zdravlja, što bi zahtevalo identifikaciju i monitoring pojave farmaceutika u vodnim ekosistemima.

Procena uticaja se često vrši za individualna farmaceutska jedinjenja, dok se farmaceutske komponente uglavnom detektuju u smešama sa ostalim antropogenim kontaminantima.

\subsection{Poreklo farmaceutika i njihova distribucija u životnu sredinu}

Poreklo farmaceutika u životnoj sredini je antropogeno i predstavlja proizvod određene ljudske aktivnosti. Aktivnosti mogu biti:
a) indrustrijska proizvodnja farmaceutika,
b) iz domaćinstva i bolnica,
c) iz poljoprivrede (stočarstvo, ribarstvo).

Farmaceutici se na osnovu njihove namene i biološke aktivnosti mogu podeliti na:
a) antibiotike,
b) alergene,
c) antipiretike,
d) antihistaminike,
e) antineoplastike,
f) antiinflamatorne lekove.

Najznačajniji put kojim farmaceutici dospevaju u životnu sredinu (slika 1) su komunalne otpadne vode iz domaćinstava i bolnica. Prilikom konzumiranja, metabolički procesi koji se odvijaju u organizmu stvaraju metabolite koji su često polarniji od polaznog jedinjenja, što omogućava njihovu bolju rastvorljivost u vodi, a time i često veću toksičnost od polazne supstance. Farmaceutici se izlučuju delimično transformisani, pri čemu se oko $50 \%$ farmaceutika izluči u neizmenjenom obliku [5].

Metaboliti poseduju sposobnost ponovne transformacije $u$ životnoj sredini i procesima prečišćavanja voda.

Aktivne komponente lekova (APIs - Active pharmaceutical ingredients) predstavljaju module sa različitom funkcionalnošću, fizičko-hemijskim i biološkim svojstvima. Razvijeni su i primenjuju se zbog svoje manje ili veće specifične biološke aktivnosti.

U najvećem broju slučajeva radi se o polarnim jedinjenjima sa molekulskom masom u opsegu 200-500 ili 1.000 Da. Farmaceutici pripadaju grupi polutanata, mikropolutanata, jer se u akvatičnoj sredini detektuju u mikrogramskim ( $\mu \mathrm{g}$ dm-3) i nanogramskim (ng dm-3) koncentracijama.

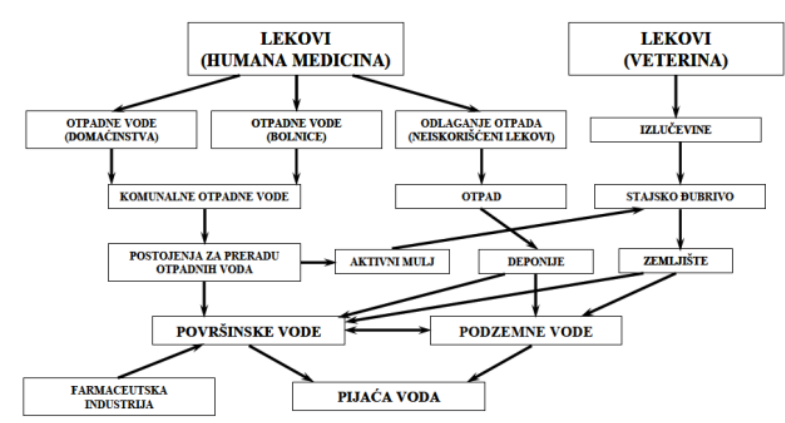

Slika 1. Putevi kojima farmaceutici dospevaju u površinske i podzemne vode (heberer, 2002)

Dalja sudbina ostataka farmaceutika u životnoj sredini zavisi od hemijskih osobina aktivne supstance. Zbog postojanja raznih funkcionalnih grupa u molekulu aktivne supstance farmaceutika, kao što su karboksilna, hidroksilna, aldehidna ili amino grupa, kapacitet adsorpcije molekula za čvrstu matricu, kao što je sediment, zavisi od $\mathrm{pH}$ sredine i sastojaka čvrste matrice.

Kada je reč o vodenoj sredini, supstance podležu abiotičkoj (hidroliza i fotoliza) ili biotičkoj transformaciji.

\subsection{Ibuprofen}

\subsubsection{Antiinflamatorni lekovi bez steroida $\mathbf{i}$ analgetici}

Nesteroidni antiinflamatorni lekovi (NSAID) primarno smanjuju upalu, dok se analgetici (AN) naširoko koriste za olakšavanje bola. Antiinflamatorni lekovi bez steroida su naproksen, ketoprofen, diklofenak, fenoprofen, indometacin i ibuprofen, a analgetici su acetaminofen (paracetamol), acetilsalicilna kiselina (aspirin) i opoidni analgetici kao što je morfijum.

Među najčešće proučavanim su diklofenak, ketoprofen, ibuprofen, naproksen i paracetamol. Njihova široka upotreba je uslovljena time što ne uzrokuju vrtoglavicu, respiratorni zastoj ili zavisnost. Ovi lekovi ublažavaju bol i upalu tako što blokiraju ciklo-oksigense (COX), enzime koji su najbitniji za proizvodnju prostaglandina.

U razvijenim zemljama, procenjena potrošnja lekova je u rasponu od nekoliko hiljada tona. Tabela 1 pokazuje relativnu potrošnju ibuprofena (IBF), ketoprofena i naproksena u nekoliko evropskih zemalja u skorije vreme.

Tabela br. 1 Relativna potrošnja ibuprofena, ketoprofena i naproksena u razvijenim evropskim zemljama

\begin{tabular}{|c|c|c|}
\hline Jedinjenje & Potrošnja (t/god) & Zemlja \\
\hline \multirow{4}{*}{ IBF } & 162 & Engleska (2000) \\
\cline { 2 - 3 } & 25 & Svajcarska(2004) \\
\cline { 2 - 3 } & 70 & Finska (2002) \\
\cline { 2 - 3 } & 345 & Nemačka (2001) \\
\cline { 2 - 3 } & 14,2 & Australija(1998) \\
\hline \multirow{4}{*}{ KTF } & 1,4 & Finska (2002) \\
\cline { 2 - 3 } & 0,25 & Svajcarska (2002) \\
\hline \multirow{4}{*}{ NAP } & 35 & Engleska (2002) \\
\cline { 2 - 3 } & 6,7 & Finska (2002) \\
\cline { 2 - 3 } & 22,8 & Australija (1998) \\
\hline
\end{tabular}


$\mathrm{Na}$ osnovu ove tabele i pregleda literature, nesteroidni antiinflamatorni lekovi su predstavljeni ibuprofenom (IBF) i sa nekoliko drugih jedinjenja zato što su najčeše korišćeni i lako dostupni. Koncentracije ovih lekova su najčešće očitane $\mathrm{u}$ redu veličine od $\mu \mathrm{g} / \mathrm{l} \mathrm{u}$ vodnoj sredini i podzemnim vodama. Niže koncentracije se generalno pojavljuju u podzemnim vodama, a zatim u fabrikama za preradu otpadnih voda zbog razređivanja i potencijalnog uklanjanja prirodnim putem, hidrolizom, sorpcijom, biodegradacijom ili fotolizom. Farmaceutička jedinjenja mogu pretrpeti biološku, hemijsku ili fizičko-hemijsku transformaciju u vodi, čak i ako su proizvedeni da istrpe mikrobiološku degradaciju i ostanu hemijski stabilni. Farmaceutička jedinjenja se transformišu prvenstveno $u$ površinskim vodama gde dominira direktna ili indirektna fotodegradacija.

\section{FOTOKATALIZA}

Tokom prethodnih nekoliko decenija svedoci smo veoma brzog rasta istraživačkih aktivnosti na polju zaštite životne sredine, kao posledice pooštravanja zakonske regulative od strane društvenih, socijalnih i političkih međunarodnih zakonodavnih organa (Andreozzi et al., 1999). Veliki broj istraživanja posvećenih iznalaženju rešenja ovog problema ukazalo je na izuzetan potencijal posebne klase oksidacionih tehnika, nazvanih unapređeni procesi oksidacije (AOP), koji svoje dejstvo ispoljavaju na temperaturama blizu sobne i pri atmosferskom pritisku. Iako koriste različite reakcione procedure, svi ovi procesi imaju zajedničku osobinu da proizvode hidroksil-radikale $(\bullet \mathrm{OH})$. Ovi radikali su visoko elektrofilni i "napadaju" veliki broj organskih molekula sa konstantama brzina $u$ rasponu od 106-109M-1s-1.

Odlikuje ih takođe i mala selektivnost napada, što predstavlja korisnu osobinu za oksidant koji se koristi u tretmanu otpadnih voda i za rešavanje problema zagađenja. Prilagodljivost ovih procesa je takođe istaknuta činjenicom da oni nude različite načine za proizvodnju $\cdot O H$ radikala, što omogućava bolju usklađenost sa specifičnim zahtevima svakog pojedinačnog tretmana.

Unapređeni procesi oksidacije koji se najčešće koriste za dekompoziciju farmaceutika su: heterogena fotokataliza, ozonacija, Fenton i foto-Fenton oksidacija, peroksinacija $\left(\mathrm{O}_{3} / \mathrm{H}_{2} \mathrm{O}_{2}\right)$, elektroliza, sonoliza (ultrazvučno ozračivanje) i oksidacija vlažnim vazduhom.

Svaki od ovih postupaka dekompozicije toksičnih farmaceutskih polutanata ima svoje prednosti za specifične aplikacije, ali se po efikasnosti i broju objavljenih naučnih studija izdvaja postupak heterogenog fotokatalitičkog razlaganja štetnih materija.

\section{EKSPERIMENTALNI DEO}

\subsection{Priprema standardnog rastvora}

Standardni rastvor ibuprofena je napravljen razlaganjem $10 \mathrm{mg}$ analitičkog standarda u $50 \mathrm{~mL}$ acetonitrila (dobijena koncentracija je iznosila $200 \mathrm{mg} / \mathrm{l}$ ). Izabrana početna koncentracija ibuprofena je iznosila 5,8 i 5,4 mg/l. Ciljana koncentracija je dobijena razblaživanjem standardnog rastvora u $100 \mathrm{ml}$ destilovane vode.

\subsection{Fotokatalitički eksperiment}

$\mathrm{Na}$ analitičkoj vagi je u erlenmajeru odmereno po $40 \mathrm{mg}$ nanokatalizatora. Uzorak je postavljen na magnetnoj mešalici i lampa sa UV zračenjem je upaljena, što se moze videti na slici.2.

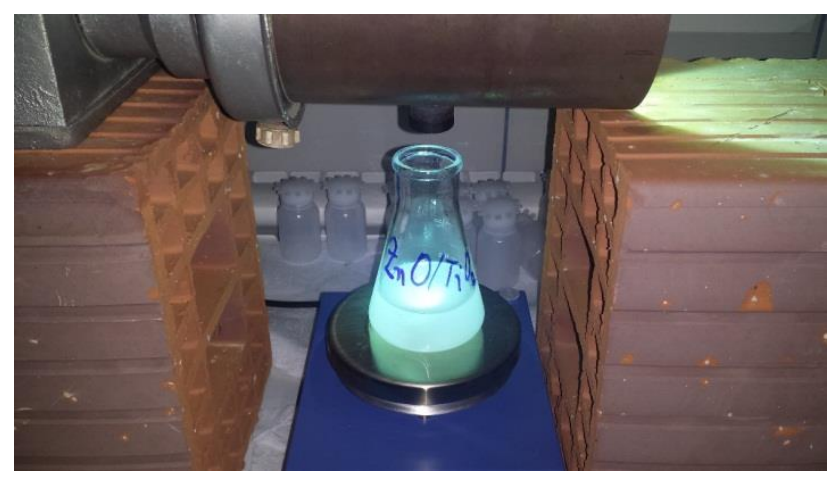

Slika 2: Prikaz uzorka na magnetnoj mešalici pri upaljenoj UV lampi

Pre fotokatalitičkog procesa uzet je jedan blank bez prisustva katalizatora. Vremenski interval uzimanja uzoraka od $10 \mathrm{ml}$, bio je od 5-60 minuta. Svi uzorci su profiltrirani kroz filter papir.

Uzorci koji su sadržili su dodatno profiltrirani kroz 0,45 $\mu \mathrm{m}$ Syringe filtere. $1 \mathrm{ml}$ svakog od alikvota je prenešen $\mathrm{u}$ HPLC vijale od 1,5 ml. Nakon pripremljenih uzoraka, uzorci su analizirani na uređaju za tečnu hromatografiju pod visokim pritiskom.

HPLC metoda za analizu ibuprofena se sastoji od dve mobilne faze: $50 \% 0,1 \%$ sirćetne kiseline u ultrapure vodi i $50 \%$ acetonitrila.

Razdvajanje je izokratsko i retenciono vreme ibuprofena je iznosila 11 minuta $\left(\mathrm{r}_{\mathrm{T}}=11 \mathrm{~min}\right)$. Talasna dužina je podešena na $220 \mathrm{~nm}$, a protok na $0,8 \mathrm{~mL} / \mathrm{min}$. Rezultati su prikazani u tabeli 2 .

Tabela 2: Zavisnost koncentracije i efikasnosti dekompozicije ibuprofena od vremena ozračivanja

\begin{tabular}{|l|l|l|l|l|}
\hline $\begin{array}{l}\text { Vreme } \\
\text { zračenja }\end{array}$ & $\begin{array}{l}\text { Površina } \\
\text { ispod pika }\end{array}$ & Koncentracija & $\begin{array}{l}\text { Procenat } \\
\text { uklanjanja }\end{array}$ & $\%$ \\
\hline 0 & 154,2 & 5,47 & 0,00 & 0,03 \\
\hline 5 & 120,9 & 4,24 & 0,23 & 22,55 \\
\hline 10 & 71,6 & 2,41 & 0,56 & 55,90 \\
\hline 20 & 50,5 & 1,63 & 0,70 & 70,17 \\
\hline 30 & 46,4 & 1,48 & 0,73 & 72,94 \\
\hline 40 & 46,2 & 1,47 & 0,73 & 73,08 \\
\hline 50 & 24,8 & 0,68 & 0,88 & 87,55 \\
\hline 60 & 18,1 & 0,43 & 0,92 & 92,08 \\
\hline
\end{tabular}

Grafička zavisnost relativne promene koncentracije ibuprofena od vremena ozračivanja prikazana je na slici 3., dok je na slici 4. predstavljena vremenska zavisnost efikasnosti fotokatalitičke reakcije degradacije ibuprofena pomoću katalizatora (linije su orijentacione). 


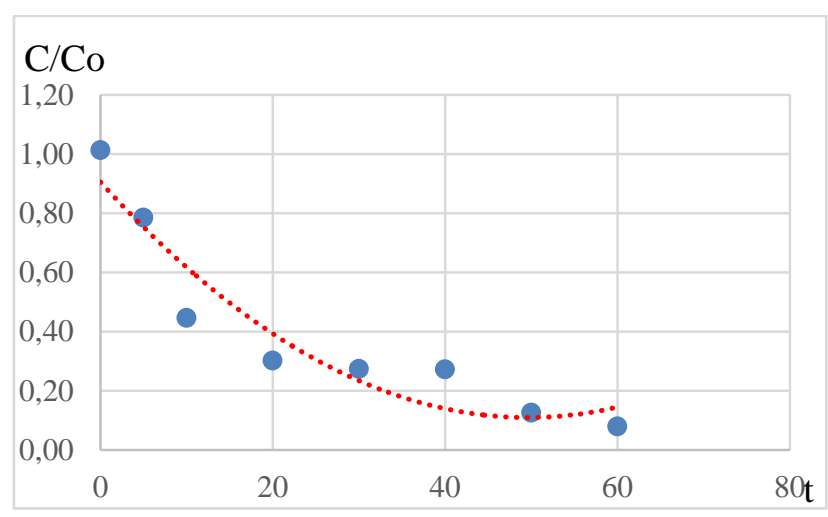

Slika 3: Zavisnost relativne promene koncentracije ibuprofena od vremena

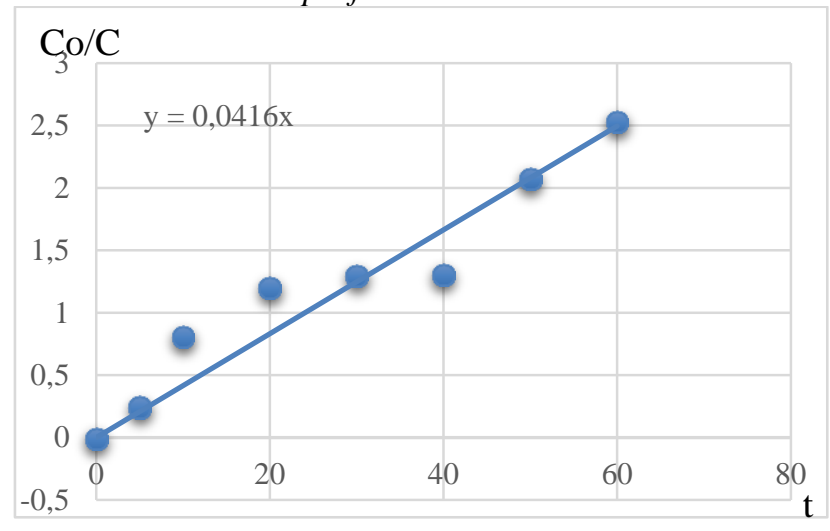

Slika 4: Efikasnost fotodegradacije ibuprofena

\section{ZAKLJUČAK}

Prilikom konzumiranja farmaceutika, metabolički procesi koji se odvijaju u organizmu ljudi i životinja dovode do strukturnih promena pri čemu nastaju metaboliti koji su često polarniji od polaznog jedinjenja, što omogućava njihovu bolju rastvorljivost u vodi, a time i često veću toksičnost od polazne supstance. Metaboliti poseduju sposobnost ponovne transformacije u životnoj sredini i procesima prečišćavanja voda.

Sudbina koju će farmaceutici imati dospevanjem u životnu sredinu zavisi od hemijskih osobina aktivne supstance, $\mathrm{pH}$ vrednosti sredine kao i sastojaka matrice za koju se vrši adsorpcija, prisustva i biološke aktivnosti prisutne mikroflore čijoj transformaciji podležu i drugih faktora.

$\mathrm{U}$ okviru rada je opisana fotodegradacija ibuprofena (IBP) u vodenom rastvoru putem nanokatalizatora $\mathrm{ZnO} / \mathrm{TiO}_{2}$.

Eliminisan je uticaj adsorpcije na razgradnju ibuprofena, merenjem promene njegove koncentracije i efikasnosti dekompozicije u zavisnosti od vremena adsorpcije (mešanja) pri uslovima optimalne osvetljenosti $\mathrm{i}$ na sobnoj temperaturi.

Potom je eksperiment ponovljen u mraku i pod dejstvom ultraljubičastog zračenja, pri čemu je konstatovano da mešavina nanokatalizatora poseduje izrazite fotokatalitičke sposobnosti: već nakon 10 minuta od početka eksperimenta koncentracija ibuprofena smanjila se gotovo na polovinu, da bi nakon jednog časa efikasnost degradacije iznosila čitavih $92 \%$.
Dobijeni rezultati ukazuju na opravdanost kombinovanja cink oksida sa titanijum (II) oksidom u cilju povećanja efikasnosti fotokatalitičkog procesa razgradnje ibuprofena i otvaraju perspektivu da se nekim drugim mešavinama ovi rezultati mogu i poboljšati.

$\mathrm{Na}$ osnovu eksperimentalnog istraživanja sprovedenog $\mathrm{u}$ laboratorijskim uslovima može se zaključiti da je efikasnost uklanjanja ibuprofena primenom mešavine anokatalizatora veoma dobra, a proces adsorpcije pogodna metoda uklanjanja farmaceutika u tretmanima vode.

\section{LITERATURA}

[1] Kolaković S, Vujović svetlana. 2011. "Tretman otpadnih voda".

[2] Saad L, and Riad M. 2008. Characterization of various zinc oxide catalysts and their activity in the dehydration-dehydrogenation of isobutanol. Journal of the Serbian Chemical Society 73(6): 997-1009.

[3] Glassmeyer S.T, Shoemaker J.A. 2005. Effects of chlorination on the persistence of pharmaceuticals in the environment. The Bulletin of Environmental Contamination and Toxicology 74, 24-31.

[4] Ternes T. 1998. Occurrence of drugs in German sewage treatment plants and rivers. Water research 32(11): 3245-3260.

[5] Hirsch R, Ternes T, Heberer K, Kratz K. 1999. Occurance of antibiotics in the aquatic environment. Wiesbaden and Mainz, Germany.

[6] Andreozzi R, Caprio V, Insola A, Marotta R. 1999. Advanced oxidation processes (AOP) forwater purification and recovery. Catalysis Today 53(1999): 51-59.

\section{Kratka biografija:}

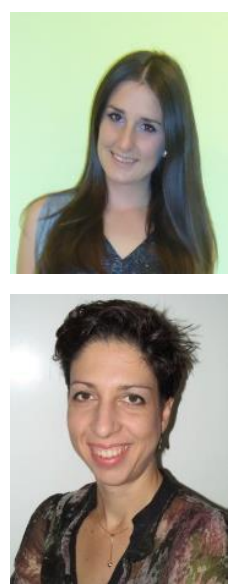

Natalija Mišanović rođena je u Doboju u Bosni i Hercegovini. Na Fakultetu Tehničkih Nauka diplomirala je 2014, a Master rad na Fakultetu tehničkih nauka iz oblasti Inženjerstva zaštite životne sredine odbranila je 2018.god.

Dr Dragana Štrbac, vanredni profesor na Fakultetu tehničkih nauka u Novom Sadu, na Katedri za Inženjerstvo zaštite životne sredine. Koautor je 21 radova sa SCI liste $\mathrm{i}$ 83 drugih radova i saopštenja. 